\title{
Chromosomal analysis of blastocysts from balanced chromosomal rearrangement carriers
}

\author{
Baoheng Gui ${ }^{1}$, Zhongyuan Yao ${ }^{1}$, Yanping $\mathrm{Li}^{2}$, Donge Liu ${ }^{2}$, Nenghui Liu ${ }^{2}$, Yan Xia ${ }^{1}$, Yanru Huang ${ }^{1}$, \\ Libin Mei ${ }^{1}$, Ruiyu Ma ${ }^{1}$, Sijia $\mathrm{Lu}^{3}$, Desheng Liang ${ }^{1}$ and Lingqian $\mathrm{Wu}^{1}$ \\ ${ }^{1}$ The State Key Laboratory of Medical Genetics of China, Central South University, No. 110 Xiangya Road, Changsha, \\ Hunan 410008, China ${ }^{2}$ The Reproductive Medical Center of Xiangya Hospital, Central South University, \\ No. 87 Xiangya Road, Changsha, Hunan 410008, China and ${ }^{3}$ Yikon Genomics Co. Ltd, 1 China Medical Avenue, \\ Taizhou, Jiangsu 225300, China \\ Correspondence should be addressed to LWu; Email: wulingqian@sklmg.edu.cn
}

\begin{abstract}
Balanced chromosomal rearrangements (CRs) are among the most common genetic abnormalities in humans. In the present study, we have investigated the degree of consistency between the chromosomal composition of the blastocyst inner cell mass (ICM) and trophectoderm (TE) in carriers with balanced CR, which has not been previously addressed. As a secondary aim, we have also evaluated the validity of cleavage-stage preimplantation genetic diagnosis (PGD) based on fluorescence in situ hybridization (FISH) of blastocysts from CR carriers. Blastocyst ICM and TE were screened for chromosomal aneuploidy and imbalance of CR-associated chromosomes based on whole-genome copy number variation analysis by low-coverage next-generation sequencing (NGS) following single-cell wholegenome amplification by multiple annealing and looping-based amplification cycling. The NGS results were analyzed without knowledge of cleavage-stage FISH results. NGS results for blastocyst ICM and TE from CR carriers were $86.49 \%$ (32/37) consistent. Of the 1702 $(37 \times 46)$ chromosomes examined, 99.47\% (1693/1702) showed consistency. However, only $40.0 \%(18 / 45)$ of all embryos had consistent results for chromosomes involved in CR, as determined by blastocyst NGS and cleavage-stage FISH. Of the 85 CR-affected chromosomes analyzed by FISH, 37.65\% (32/85) were incongruous with NGS results, with $87.5 \%(28 / 32)$ showing imbalanced composition by FISH but balanced composition by NGS. These results indicate that chromosomal composition of blastocyst ICM and TE in balanced CR carriers is highly consistent, and that PGD based on cleavage-stage FISH is inaccurate; therefore, using blastocyst TE biopsies for NGS-based PGD is recommended for identifying chromosomal imbalance in embryos from balanced CR carriers.

Reproduction (2016) 151 455-464
\end{abstract}

\section{Introduction}

Balanced chromosomal rearrangements (CRs), which include Robertsonian translocation (Rob), reciprocal translocation (Rcp) and inversion (Inv), are among the most common genetic abnormalities in humans, with an incidence of around $0.19 \%$ of newborns (Hamerton et al. 1972, 1975, Jacobs et al. 1974), a rate that is higher among infertile couples (De Braekeleer \& Dao 1991) and patients with implantation failure and recurrent miscarriage (Campana et al. 1986, Stern et al. 1999). Preimplantation genetic diagnosis (PGD) based on fluorescence in situ hybridization (FISH) (Conn et al. 1998, Van Assche et al. 1999, Coonen et al. 2000, Alves et al. 2002, Otani et al. 2006, Bernicot et al. 2010, Bernicot et al. 2012, Ko et al. 2013) and microarray-based profiling (Alfarawati et al. 2011, Fiorentino et al. 2011, Treff et al. 2011, Colls et al. 2012, van Uum et al. 2012, Huang et al. 2013, Tan et al. 2013) are widely used to select normal/balanced embryos for CR carriers to transfer.
Chromosomal mosaicism is frequently observed in cleavage-stage embryos when screening for aneuploidy (Bielanska et al. 2002, van Echten-Arends et al. 2011). Data from single-cell comparative genomic hybridization $(\mathrm{CGH})$ have also revealed that cleavage-stage embryos from translocation carriers exhibit mosaic patterning of the translocated chromosomes, with their distribution varying considerably in different blastomeres even from the same embryo (Malmgren et al. 2002). This can compromise the accuracy of genetic diagnoses that are based on cleavage-stage embryos. An alternative approach is to use blastocyst trophectoderm (TE) biopsies when performing PGD for CR carriers (Huang et al. 2013). However, very little is known about the consistency between the inner cell mass (ICM) and TE of blastocysts from CR carriers in terms of chromosomal composition. Previous studies in cleavage-stage embryos have found a higher frequency of mosaicism and abnormal segregation for translocation-associated chromosomes as compared to other chromosomes that 
were not associated with translocation from the same embryo (Iwarsson et al. 2000) or embryos from couples with a normal karyotype (Emiliani et al. 2003). Some explanations have been proposed to explain the phenomenon, for example, a higher propensity of CR-associated chromosomes to missegregate as a result of rearrangements themselves during mitosis/meiosis (Iwarsson et al. 2000) or the greater likelihood of acrocentric chromosomes (such as chromosomes 13, $14,15,21$ and 22) that are frequently involved in translocation to missegregate and show numerical abnormalities (Boue et al. 1985), resulting in more diverse cell lines (Iwarsson et al. 2000, Emiliani et al. 2003). Thus, mosaicism may be common in blastocysts from $C R$ carriers, especially for CR-associated chromosomes. Previous investigations indicated the chromosomal composition of ICM and TE from patients without known chromosomal abnormalities, for example, balanced CR shows a high degree of consistency, and TE testing is therefore unlikely to be confounded by mosaicism (Fragouli et al. 2008, Northrop et al. 2010, Capalbo et al. 2013b). However, microarray analyses of the TE and ICM have detected mosaicism in a high proportion of aneuploid blastocysts, suggesting that TE biopsies do not accurately predict the chromosomal content of the ICM in aneuploid embryos (Liu et al. 2012). Thus, before widespread clinical application of TE biopsies in PGD for CR carriers, it is worth noting whether TE represents the state of ICM in blastocysts of CR carriers.

Despite the clinical application of cleavage-stage FISH in PGD for CR carriers, there is little evidence to support its validity in predicting the chromosomal composition in later development stages. Previous studies have shown that aneuploidy screening of cleavage-stage embryos by FISH yields results that are poorly consistent with those obtained by comprehensive chromosomal screening (CCS) of corresponding blastocysts (Northrop et al. 2010). These discrepancies may be due to mosaicism, FISH artifacts or self-correction of chromosomal segregation errors (Munne et al. 2005b, Barbash-Hazan et al. 2009). Therefore, PGD based on cleavage-stage FISH for CR carriers may not accurately detect the imbalance of CR-associated chromosomes and effectively reflect the chromosomal composition in the corresponding blastocysts. Moreover, aneuploidy is common in embryos from CR carriers (Pujol et al. 2003), even those that are normal/balanced for CR-associated chromosomes (Pujol et al. 2006, Treff et al. 2011), and CR-associated chromosomes can exert inter-chromosomal effects during meiosis and mitosis (Lejeune 1963, Pellestor et al. 1989, Conn et al. 1998, Munne et al. 2005a), leading to an increased risk of chromosomal abnormality. As such, aneuploidy screening is recommended in parallel with the detection of CR-associated imbalances.

Emerging single-cell next-generation sequencing (NGS) technology provides a comprehensive approach to chromosomal analysis (Zong et al. 2012) and has shown clinical applicability in concurrent screening for comprehensive chromosomal aneuploidy (Fiorentino et al. 2014a,b, Huang et al. 2014, Wells et al. 2014) and chromosomal/segmental imbalances in CR carriers (Wang et al. 2014). The high throughput, automation and cost-effectiveness of NGS make it a promising alternative to currently available methods that can potentially improve the efficiency of CCS.

The primary aim of this study was to investigate the consistency of chromosomal composition between the ICM and TE of blastocysts from CR carriers using NGSbased concurrent screening of chromosomal aneuploidy and CR-associated chromosomal imbalances, and to evaluate the validity of cleavage-stage FISH-based PGD for CR carriers by examining the corresponding blastocysts. As a secondary aim, this study assessed whether NGS-based PGD using TE biopsies accurately reflects ICM chromosomal composition.

\section{Materials and methods}

\section{Patients and embryos}

Single blastomeres were biopsied from embryos obtained from $\mathrm{CR}$ carriers and subjected to FISH-based PGD. Blastocysts previously diagnosed as unbalanced by FISH or exhibiting developmental arrest were donated for research. A total of 51 blastocysts from 13 couples were evaluated between December 2013 and October 2014 at the Reproductive Medical Center of Xiangya Hospital, China. Basic genetic information is provided in Table 1.

\section{Ethical approval}

This study was approved by the Institutional Review Board of Xiangya Hospital, Central South University. All subjects provided written informed consent for study participation.

\section{Embryo culture, blastomere biopsy and FISH analysis}

Embryos were cultured in G1 medium (Vitrolife, Kungsbacka, Sweden) at $37{ }^{\circ} \mathrm{C}$ in a humidified atmosphere of $6 \% \mathrm{CO}_{2}$. As a routine PGD procedure, good-quality embryos from the twopronuclear zygotes with $\geq 6$ cells and $\leq 15 \%$ fragments on day 3 (Fig. 1A) were biopsied for FISH analysis of CR-affected chromosomes. The biopsy was performed by opening a hole in the zona pellucida with a series of single, millisecond pulses delivered from a 1-3- $\mu \mathrm{m}$ diode laser (Hamilton-Thorne Research, Beverly, MA, USA) in $\mathrm{Ca}^{2+}-\mathrm{Mg}^{2+}$-free hydroxyethyl piperazineethane sulfonic acid (HEPES)-buffered human tubal fluid medium (Irvine Scientific, Santa Ana, CA, USA). Single blastomeres were aspirated into the biopsy pipette (Humagen, Charlottesville, VA, USA) and detached from the embryos. Embryos were transferred to G2 medium (Vitrolife) and cultured until days 5-6 using the same conditions after biopsy. Biopsied blastomeres were subjected to interphase nuclear FISH, as described previously (Ko et al. 2013). All probes (Table 1) were prepared from our laboratory's repository of 
Table 1 Carrier karyotypes and FISH probes used for PGD.

\begin{tabular}{|c|c|c|c|c|c|}
\hline Karyotype & $\begin{array}{l}\text { No. of } \\
\text { patients }\end{array}$ & $\begin{array}{c}\text { No. of } \\
\text { embryos }\end{array}$ & $\begin{array}{c}\text { Translocated segment }^{\mathrm{a}} \\
\text { of } \mathrm{Chr} \mathrm{A}^{\mathrm{b}}(\mathrm{Mb})\end{array}$ & $\begin{array}{l}\text { Translocated segment } \\
\text { of Chr } \mathbf{B}^{\mathrm{C}}(\mathrm{Mb})\end{array}$ & Probes \\
\hline 45, XX, der(13;14)(q10;q10) & 3 & 10 & 97.3 & 89.7 & LSI $13 q$ SO, LSI $14 q$ SG \\
\hline 45, XY, der(13;14)(q10;q10) & 4 & 15 & 97.3 & 89.7 & LSI $13 q$ SO, LSI 14q SG \\
\hline 45, XX, der(14;22)(q10;q10) & 1 & 9 & 89.7 & 36.6 & LSI 14q SG, LSI 22q SO \\
\hline $46, X Y, t(1 ; 19)(p 36 ; q 13)$ & 1 & 3 & 28.0 & 26.7 & Tel $1 \mathrm{p} \mathrm{SG}$, Tel $1 \mathrm{q}$ SR, Tel $19 \mathrm{q}$ SO \\
\hline $46, X X, t(8 ; 22)(q 24.1 ; q 11.2)$ & 1 & 3 & 28.7 & 33.4 & LSI $8 p$ SO, Tel $8 q$ SR, Tel 22q SG \\
\hline $46, X Y, t(1 ; 10)(\mathrm{p} 34 ; \mathrm{q} 26)$ & 1 & 6 & 46.8 & 16.4 & Tel 1p SG, Tel 1q SR, Tel 10q SO \\
\hline $46, X X, \operatorname{inv}(11)(p 15 q 11)$ & 1 & 1 & 21.7 & 81.3 & LSI 11p SO, Tel 11q SG \\
\hline $46, X Y, \operatorname{inv}(20)(p 13 q 13.1)$ & 1 & 4 & 5.1 & 21.3 & LSI $20 p$ SG, Tel 20q SO \\
\hline
\end{tabular}

${ }^{a}$ Expected minimum size of the imbalance in mega bases (Mb) according to the University of California Santa Cruz (UCSC) database (http://genome.

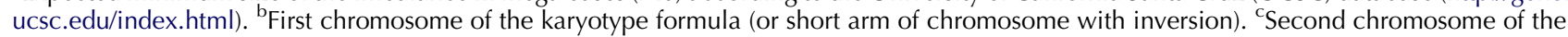
karyotype formula (or long arm of chromosome with inversion).

bacterial artificial chromosome libraries and labeled with fluorescein using a Nick-Translation kit (Abbott Molecular), according to the manufacturer's instructions.

\section{Blastocyst biopsy and whole-genome amplification}

Blastocysts were biopsied as described previously (Northrop et al. 2010), with slight modifications. TE and ICM samples (each consisting of 5-8 cells) from expanded blastocysts (Fig. 1C and E) were biopsied and evaluated for chromosomal mosaicism. The ICM was judged as being free of TE cells by morphological assessment carried out by an embryologist. For early-stage blastocysts that were not expanded and did not show distinguishable ICM and TE, a single sample was biopsied as described above. Samples were washed three times in $\mathrm{Ca}^{2+}-\mathrm{Mg}^{2+}$-free $1 \times$ PBS and placed in nuclease-free $0.2 \mathrm{ml}$ PCR tubes for whole-genome amplification (WGA). Samples were amplified by the multiple annealing and looping-based amplification cycling single-cell WGA method, which has been validated for PGD/preimplantation genetic screening
(Huang et al. 2014), using a kit (Yikon Genomics, Taizhou, China) according to the manufacturer's protocol.

\section{NGS and chromosomal copy number variation analysis}

The amplified genome of each blastocyst TE and ICM sample was sequenced using an Illumina HiSeq 2500 platform for a total of two million reads. Chromosomal copy number variation analysis was carried out, as described previously (Zong et al. 2012). Reads were aligned to the human genome hg19 reference sequence and filtered to remove reads that were unmapped, duplicated or had low mapping scores. Filtered reads were counted and displayed with a bin size of $1 \mathrm{Mb}$ across the whole-genome. Data in each bin were normalized by guanine-cytosine (GC) content to in silico reference data in order to remove bias. Copy number gain from two to three copies of a genome segment resulted in a 50\% increase in read counts as compared to those for normal chromosomes, and copy number loss from two copies to one copy resulted in a $50 \%$ decrease in read counts. Copy number analysis was

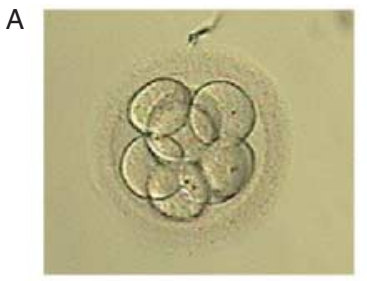

C

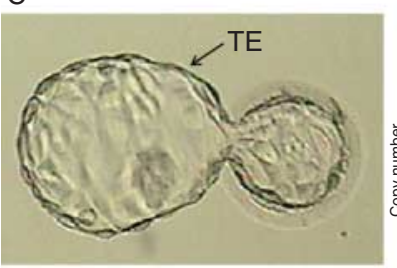

E

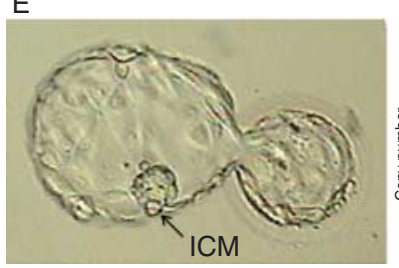

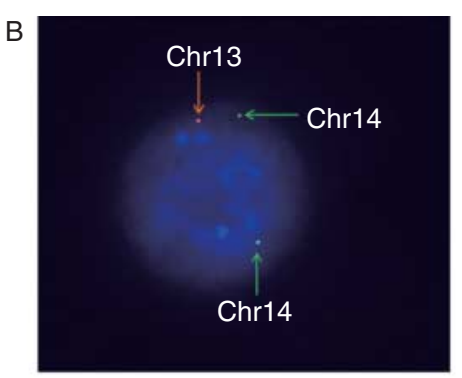

D

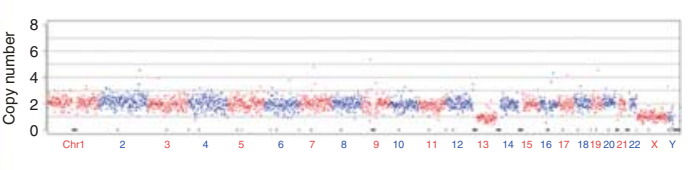

F

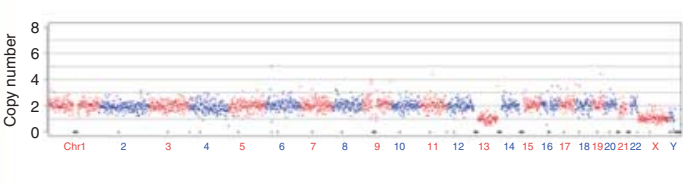

Figure 1 Fluorescence in situ hybridization (FISH) and next-generation sequencing (NGS) analyses of an embryo from a Robertsonian translocation carrier. (A) Micrograph of an 8-cell embryo on day 3 from a der $(13 ; 14)(q 10 ; q 10)$ carrier. (B) Interphase nuclear FISH of the same 8-cell embryo showing monosomy of chromosome (Chr) 13. (C) Micrograph of the same embryo at the blastocyst stage with trophectoderm (TE) being in focus. The TE was biopsied for whole-genome amplification (WGA) and NGS. (D) Chromosomal screening for the TE by NGS; only one copy of chromosome 13 was detected, consistent with results of the FISH analysis. (E) Micrograph of the same embryo at the blastocyst stage with inner cell mass (ICM) being in focus. The ICM was biopsied for WGA and NGS. (F) Chromosomal screening for the ICM by NGS, consistent with results of the TE. 
Table 2 FISH and NGS results of embryos from carriers with balanced rearrangement.

\begin{tabular}{|c|c|c|c|c|c|c|}
\hline \multirow[b]{2}{*}{ Embryo No. } & \multirow[b]{2}{*}{ FISH result } & \multicolumn{2}{|c|}{ NGS results } & \multirow{2}{*}{$\begin{array}{c}\text { Agreement } \\
\text { between } \\
\text { FISH and } \\
N^{2} S^{\mathrm{a}}\end{array}$} & \multirow{2}{*}{$\begin{array}{c}\text { Agreement } \\
\text { between } \\
\text { ICM and } \\
T^{b} \\
\end{array}$} & \multirow[b]{2}{*}{ Aneuploidy } \\
\hline & & ICM & TE & & & \\
\hline \multicolumn{7}{|c|}{$\begin{array}{l}\text { Rob } \\
\operatorname{der}(13 ; 14)(q 10 ; q 10)\end{array}$} \\
\hline 1 & +14 & NB & NB & $\mathrm{NO}$ & YES & NO \\
\hline 2 & -14 & NB & NB & $\mathrm{NO}$ & YES & NO \\
\hline 3 & Multi-nuclei & +2 & +2 & - & YES & YES \\
\hline 4 & -13 & $+14,+2 p(\operatorname{mos}, 40 \%)^{d}$ & +14 & $\mathrm{NO}$ & Mosaicism & Mosaicism \\
\hline 5 & +13 & -15 & -15 & NO & YES & YES \\
\hline 6 & -13 & -13 & -13 & YES & YES & NO \\
\hline 7 & $+13,-14$ & -5 & -5 & $\mathrm{NO}$ & YES & YES \\
\hline 8 & No signal & NB & NB & - & YES & $\mathrm{NO}$ \\
\hline 9 & No signal & -13 & -13 & - & YES & $\mathrm{NO}$ \\
\hline 10 & +13 & +13 & +13 & YES & YES & $\mathrm{NO}$ \\
\hline 11 & -13 & $+2,+14$ & $+2,+14$ & $\mathrm{NO}$ & YES & YES \\
\hline 12 & -14 & -14 & -14 & YES & YES & $\mathrm{NO}$ \\
\hline 13 & -13 & -13 & $\begin{aligned} &-13,+ 14 q(q 23.3-q 32.33) \\
&(\operatorname{mos}, 70 \%)^{d}\end{aligned}$ & YES & Mosaicism & $\mathrm{NO}$ \\
\hline $14^{\mathrm{e}}$ & NB & \multicolumn{2}{|r|}{ NB } & YES & - & NO \\
\hline 15 & -13 & NB & NB & $\mathrm{NO}$ & YES & NO \\
\hline 16 & No signal & $\begin{array}{r}+6 p(\operatorname{mos}, 50 \%)^{d},-13(\operatorname{mos}, \\
30 \%)^{d},+17(\operatorname{mos}, 60 \%)^{d^{d}}\end{array}$ & NB & - & Mosaicism & Mosaicism \\
\hline $17^{\mathrm{e}}$ & Multi-nuclei & \multicolumn{2}{|l|}{ 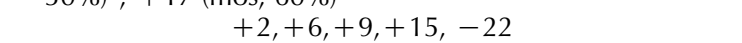 } & - & - & YES \\
\hline 18 & -14 & +13 & +13 & NO & YES & $\mathrm{NO}$ \\
\hline $19^{\mathrm{e}}$ & -13 & \multicolumn{2}{|c|}{ NB } & NO & - & $\mathrm{NO}$ \\
\hline 20 & -14 & NB & NB & NO & YES & $\mathrm{NO}$ \\
\hline 21 & -14 & -14 & -14 & YES & YES & $\mathrm{NO}$ \\
\hline 22 & +13 & NB & NB & $\mathrm{NO}$ & YES & NO \\
\hline 23 & -13 & +6 & +6 & NO & YES & YES \\
\hline $24^{\mathrm{e}}$ & -14 & \multicolumn{2}{|c|}{-8} & NO & - & YES \\
\hline \multicolumn{2}{|c|}{$\operatorname{der}(14 ; 22)(q 10 ; q 10)$} & \multicolumn{2}{|c|}{ NB } & NO & - & NO \\
\hline 26 & -14 & $\begin{array}{c}-8(\operatorname{mos}, 50 \%)^{\mathrm{d}},+17 \\
(\operatorname{mos}, 50 \%)^{\mathrm{d}}\end{array}$ & $\begin{array}{l}-8 q(q 21.2-q 24.3)(\operatorname{mos} \\
60 \%)^{d},+17(\operatorname{mos}, 50 \%)^{d}\end{array}$ & $\mathrm{NO}$ & Mosaicism & Mosaicism \\
\hline $27^{\mathrm{e}}$ & $-14,-22$ & \multicolumn{2}{|c|}{$-14,-22$} & YES & - & NO \\
\hline 28 & -22 & -22 & -22 & YES & YES & $\mathrm{NO}$ \\
\hline $29^{\mathrm{e}}$ & -14 & \multicolumn{2}{|c|}{ NB } & $\mathrm{NO}$ & - & $\mathrm{NO}$ \\
\hline $30^{\mathrm{e}}$ & -14 & \multicolumn{2}{|c|}{$-14,+16,-18$} & YES & - & YES \\
\hline 31 & -22 & -21 & -21 & NO & YES & YES \\
\hline 32 & -14 & $-2 p(p 22.3-p 25.3)$ & $-2 p(p 22.3-p 25.3)$ & $\mathrm{NO}$ & YES & segment loss \\
\hline 33 & -22 & -22 & -22 & YES & YES & $\mathrm{NO}$ \\
\hline 34 & -14 & $\begin{array}{c}-14(\operatorname{mos}, 30 \%)^{\mathrm{d}},+16 \mathrm{p} \\
(\operatorname{mos}, 40 \%)^{\mathrm{d}}\end{array}$ & $+16 \mathrm{p}(\operatorname{mos}, 30 \%)^{\mathrm{d}}$ & $\mathrm{NO}$ & Mosaicism & Mosaicism \\
\hline \multicolumn{7}{|c|}{$\begin{array}{l}\operatorname{Rcp}^{f} \\
t(1 ; 19)(p 36 ; q 13)\end{array}$} \\
\hline 35 & $-1 p,+19 q$ & $\begin{array}{l}-1 p(p 33-p 36.33),+ \\
19 q(q 13.11-q 13.43)\end{array}$ & $\begin{array}{l}-1 p(p 33-p 36.33) \\
+19 q(q 13.11-q 13.43)\end{array}$ & YES & YES & NO \\
\hline 36 & $\begin{array}{r}-1 p,-1 p \\
-19 q\end{array}$ & NB & NB & $\mathrm{NO}$ & YES & NO \\
\hline \multicolumn{2}{|c|}{$\mathrm{t}(8 ; 22)(\mathrm{q} 24.1 ; \mathrm{q} 11.2)$} & NB & NB & - & YES & NO \\
\hline $38^{\mathrm{e}}$ & $+22 q$ & \multicolumn{2}{|c|}{$+8 p(p 11-p 23.3),+8 q(q 11-q 24.11),-22 q(q 11-q 11.21)$} & $\mathrm{NO}$ & - & NO \\
\hline $39^{\mathrm{e}}$ & $-8 q$ & \multirow{2}{*}{\multicolumn{2}{|c|}{$\begin{array}{c}-8 q(q 24.11-q 24.3),+22 q(q 11.21-q 13.33) \\
+8 q(q 24.11-q 24.3),-22 q(q 11.21-q 13.33),+2,+11,+17\end{array}$}} & NO & - & NO \\
\hline $\begin{array}{l}40^{\mathrm{e}} \\
\mathrm{t}(1 ; 10)(\mathrm{p} 34 ;\end{array}$ & $+8 q,-22 q$ & & & YES & - & YES \\
\hline 41 & $-1 p ;+10 q$ & $\begin{array}{l}-1 p(p 31.1-p 36.33) \\
+10 q(q 25.3-q 26.3)\end{array}$ & $\begin{array}{l}-1 p(p 31.1-p 36.33) \\
+10 q(q 25.3-q 26.3)\end{array}$ & YES & YES & NO \\
\hline 42 & $+1 p,-10 q$ & $\begin{array}{l}+1 p(p 31.1-p 36.33) \\
-10 q(q 25.3-q 26.3),-21\end{array}$ & $\begin{array}{l}+1 p(p 31.1-p 36.33) \\
-10 q(q 25.3-q 26.3),-21\end{array}$ & YES & YES & YES \\
\hline 43 & $-10 q$ & -21 & -21 & $\mathrm{NO}$ & YES & YES \\
\hline 44 & $+1 p,-10 q$ & $\begin{array}{l}+1 p(p 31.1-p 36.33) \\
-10 q(q 25.3-q 26.3),+22\end{array}$ & $\begin{array}{l}+1 p(p 31.1-p 36.33) \\
-10 q(q 25.3-q 26.3),+22\end{array}$ & YES & YES & YES \\
\hline $45^{\mathrm{e}}$ & $+1 p,-10 q$ & $+1 p(p 31.1-p 36.33)$ & $-10 q(q 25.3-q 26.3)$ & YES & - & NO \\
\hline 46 & $-10 q$ & NB & NB & $\mathrm{NO}$ & YES & NO \\
\hline $\begin{array}{l}\operatorname{Inv}^{f} \\
\operatorname{inv}(11)(p 15 ;\end{array}$ & & & & & & \\
\hline 47 & $-11 p,-11 q$ & $-X,-X /-X,-Y$ & $-X,-X /-X,-Y$ & $\mathrm{NO}$ & YES & YES \\
\hline
\end{tabular}


Table 2 Continued.

\begin{tabular}{|c|c|c|c|c|c|c|}
\hline \multirow[b]{2}{*}{ Embryo No. } & \multirow[b]{2}{*}{ FISH result } & \multicolumn{2}{|c|}{ NGS results } & \multirow{2}{*}{$\begin{array}{c}\text { Agreement } \\
\text { between } \\
\text { FISH and } \\
\text { NGS }^{\mathrm{a}}\end{array}$} & \multirow{2}{*}{$\begin{array}{c}\text { Agreement } \\
\text { between } \\
\text { ICM and } \\
\text { TE }^{\mathrm{b}} \\
\end{array}$} & \multirow[b]{2}{*}{ Aneuploidy } \\
\hline & & $\mathrm{ICM}$ & TE & & & \\
\hline \multicolumn{7}{|c|}{$\operatorname{inv}(20)(p 13 ; q 13.1)$} \\
\hline 48 & $+20 p,-20 q$ & NB & NB & $\mathrm{NO}$ & YES & $\mathrm{NO}$ \\
\hline 49 & $-20 p$ & NB & NB & $\mathrm{NO}$ & YES & $\mathrm{NO}$ \\
\hline $50^{e}$ & NB & \multicolumn{2}{|c|}{ NB } & YES & - & $\mathrm{NO}$ \\
\hline $51^{\mathrm{e}}$ & NB & \multicolumn{2}{|c|}{ NB } & YES & - & $\mathrm{NO}$ \\
\hline
\end{tabular}

${ }^{a}$ Agreement indicates that the FISH result is consistent with NGS results from ICM or TE or both. ${ }^{b}$ Mosaicism refers to the incongruity of ICM and TE

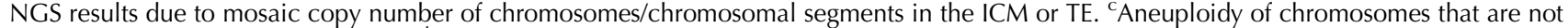
involved in balanced rearrangement. ${ }^{\mathrm{d}}$ The percentage of mosaicism (aneuploidy) is estimated on the assumption that the biopsied tissue contains two distinct cell lines (diploid and triploid, or diploid and haploid) with regard to the chromosome analyzed. ${ }^{\mathrm{e} O n l y}$ one NGS result is shown for embryos at the early blastocyst stage (without distinguishable ICM and TE). 'FISH results for embryos from carriers with reciprocal translocation and inversion are presented as gains or losses of chromosome arms based on fluorescence signals. For these embryos, FISH and NGS results were considered to be consistent when the copy number of translocation/inversion-related regions detected by NGS was consistent with that of chromosome arms inferred from fluorescence signals.

performed in a blinded manner with respect to the results of the cleavage-stage FISH analysis.

\section{Results}

A total of 37 expanded and 14 early-stage blastocysts were biopsied for NGS, with all samples yielding interpretable results in the copy number analysis. FISH results of 45 embryos were readable while the remaining six showed multiple nuclei or no signal (Table 2).

\section{Consistency between blastocyst ICM and TE}

The consistency between blastocyst ICM and TE was $86.49 \%$ (32/37) by NGS (Figs 1D, F and 2B, C, E, F); five embryos exhibited ICM or TE mosaicism (Fig. 3B, C, E and F) and were from Rob carriers, with concordance rates of $80.77 \%(21 / 26), 100 \%(8 / 8)$ and $100 \%(3 / 3)$ for blastocysts from Rob, Rcp and Inv carriers respectively (Table 2). Of the $1702(37 \times 46)$ chromosomes that were detected, 99.47\% (1693/1702) showed consistency (Table 3). Of the nine mosaic chromosomes in 26 expanded blastocysts from Rob carriers, three of a total of $26 \times 2(5.77 \%)$ were Rob-related and six of a total of $26 \times 44(0.52 \%)$ were Rob-free, representing a statistically significant difference $\left(\chi^{2}=18.320\right.$; Fisher's exact test; $P=0.005)$.

\section{Validity of cleavage-stage FISH-based PGD}

In the analysis of CR-associated chromosomes by blastocyst NGS and cleavage-stage FISH, 40.0\% (18/45) of all embryos showed concordant results, with concordance rates of $34.48 \%$ (10/29), $54.55 \%$ (6/11) and 40.0\% (2/5) for embryos from Rob, Rcp and Inv carriers respectively (Table 2 and Fig. 1B, D and F).
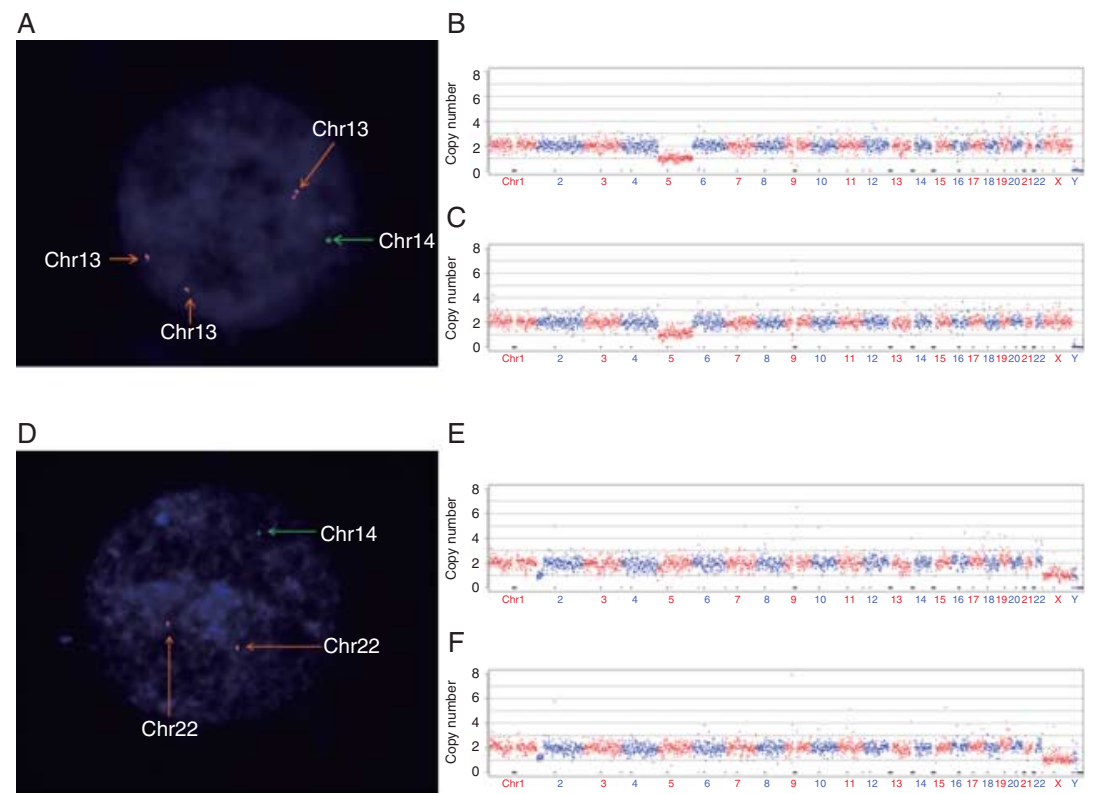

Figure 2 Disparity between results obtained by fluorescence in situ hybridization (FISH) and by next-generation sequencing (NGS). (A) FISH analysis of a cleavage-stage embryo from a der $(13 ; 14)(q 10 ; q 10)$ carrier showing trisomy of chromosome (Chr) 13 and monosomy of chromosome 14. (B) and (C) Chromosomal screening by NGS of the inner cell mass (ICM) (B) and trophectoderm (TE) (C) from the same embryo at the blastocyst stage as (A); chromosomes 13 and 14 had normal copy numbers, but monosomy was observed for chromosome 5. (D) FISH analysis of a cleavage-stage embryo from a der $(14 ; 22)(q 10 ;$ q10) carrier showing monosomy of chromosome 14. (E) and (F) Chromosomal screening by NGS of the ICM (E) and TE (F) from the same embryo at the blastocyst stage as (D); chromosome 14 had a normal copy number, but a segmental loss was detected for chromosome 2, $-2 \mathrm{p}$ (p22.3-p25.3). 

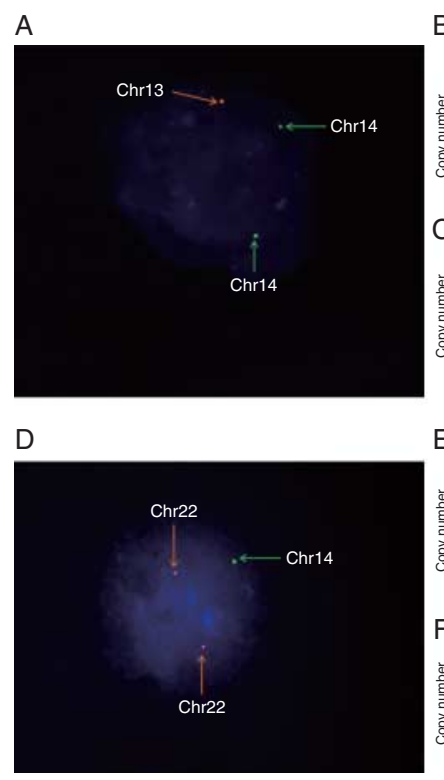

B

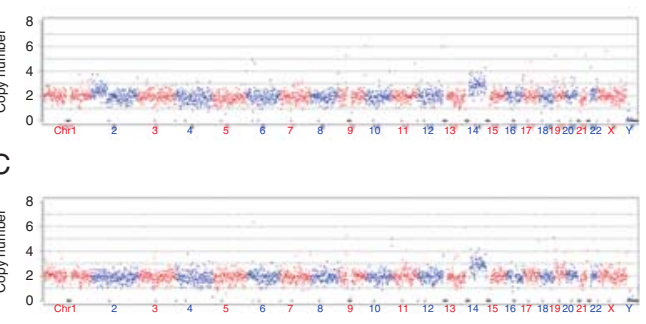

E

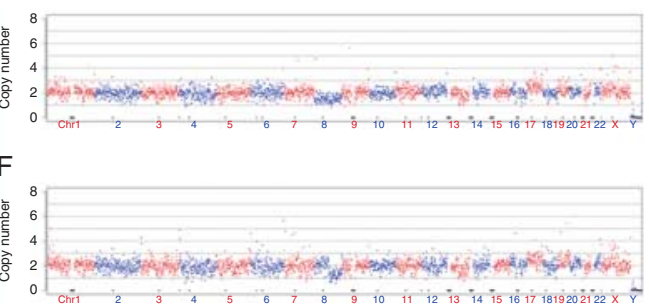

Figure 3 Disparity between results of inner cell mass (ICM) and trophectoderm (TE) copy number analyses due to mosaicism. (A) Fluorescence in situ hybridization (FISH) analysis of a cleavage-stage embryo from a der $(13 ; 14)(q 10 ; q 10)$ carrier showing monosomy of chromosome (Chr) 13 . (B) and (C) Chromosomal screening by NGS of the ICM (B) and TE (C) from the same embryo at the blastocyst stage as (A); chromosome 13 had a normal copy number, but trisomy was observed for chromosome 14. A segmental gain of chromosome $2(+2 p)$ was detected in the ICM but not the TE; however, the copy number in this region was $<3$ owing to mosaicism. (D) FISH analysis of a cleavage-stage embryo from a der $(14 ; 22)$ (q10; q10) carrier showing monosomy of chromosome 14. (E) and $(F)$ Chromosomal screening by NGS of the ICM (E) and TE (F) from the same embryo at the blastocyst stage as (D); chromosome 14 had a normal copy number, but mosaicism was observed for chromosomes 8 and 17 in the ICM and TE.
Of the 85 CR-associated chromosomes (80 chromosomes from 40 embryos of Rob/Rcp carriers and five chromosomes from five embryos of Inv carriers) analyzed by cleavage-stage $\mathrm{FISH}, 37.65 \%$ (32/85) were inconsistent with the blastocyst NGS results; of these, $87.5 \%(28 / 32)$ showed imbalanced chromosomal composition by $\mathrm{FISH}$ but balanced composition by NGS (Table 3 and Fig. 2A, B, C, D, E and F). Of the 25 chromosomes in embryos obtained from Rob/Rcp carriers (after excluding three chromosomes in embryos from Inv carriers) showing imbalanced composition by FISH but balanced composition by NGS, 80.0\% (20/25) exhibited copy number loss by FISH (Fig. 2D, E and F), in contrast to $20.0 \%$ (5/25) that exhibited copy number gain (Fig. 2A, B and C). A total of $31.91 \%$ (15/47) of embryos were abnormal, showing whole or segmental aneuploidy (Fig. 2B, C, E and F) of chromosomes that were not involved in $\mathrm{CR}$.

\section{Discussion}

This study investigated the chromosomal composition of the blastocyst ICM and TE in CR carriers by NGS and found a high degree of consistency between the two tissues $(99.47 \%$ for individual chromosomes and $86.49 \%$ for individual embryos), which is in line with previous studies of embryos from karyotypically normal couples (Fragouli et al. 2008, Northrop et al. 2010, Capalbo et al. 2013b). These findings indicate that TE biopsies reliably reflect ICM chromosomal status and can be used for PGD of CR carriers. All inconsistencies (five embryos) were attributable to chromosomal/ segmental copy number mosaicism in the ICM or TE. Embryonic mosaicism is derived from a variety of mechanisms including chromosome anaphase lagging (Coonen et al. 2004, Capalbo et al. 2013a), nondisjunction (Bean et al. 2001) or endoreplication.
Anaphase lagging could account for the vast majority of chromosome mosaicism (Coonen et al. 2004). Several checkpoints control the proper alignment of chromosomes during mitosis and meiosis and block entry into anaphase when the chromosomes are not appropriately attached to the spindle (Encalada et al. 2005, Wei et al. 2011). However, these mechanisms may be deficient to avoid all the errors, supported by findings of lagging chromosomes in human embryos (Coonen et al. 2004). These lagging chromosomes may be encapsulated into embryonic micronuclei sequestering from the blastomeres into cytoplasmic fragments (Chavez et al. 2012). Such fragments may remain or be absorbed by a neighboring blastomere (Wong et al. 2010, Chavez et al. 2012), creating euploid-aneuploid mosaicism, aneuploid mosaicism or even chaotic chromosome distribution pattern. Previous study also indicated that the lack of functional cell cycle checkpoint mechanisms may lead to chromosomal segregation errors during the mitotic divisions of human preimplantation embryos and thus to mosaicism (Harrison et al. 2000). We estimated the percentage of mosaicism (aneuploidy) on the assumption that the biopsied tissue contains two distinct cell lines (diploid and triploid or diploid and haploid) with regard to the chromosome analyzed. If the error occurs during the first mitotic divisions, the embryo would be more likely to exhibit $\sim 50 \%$ of abnormal cells (such as the ICM of embryo 26). If the abnormal cells account for $\sim 70 \%$ or only $\sim 30 \%$ of the total cells, it could be inferred that the error occurs during the later stage of embryo development (such as the ICM and TE of embryo 34) or that the embryo is subjected to aneuploidy rescue (such as the TE of embryo 13). Furthermore, we found that Rob-affected chromosomes exhibited a higher rate of mosaicism in the ICM and TE (5.77\%) than Robfree chromosomes $(0.52 \%)$, suggesting that consistency 
Table 3 Number of individual chromosomes with consistent/inconsistent results by FISH and NGS or between ICM and TE of embryos from balanced rearrangement carriers.

\begin{tabular}{|c|c|c|c|c|c|c|c|}
\hline \multirow[b]{2}{*}{ Embryo No. } & \multicolumn{3}{|c|}{ Agreement between FISH and NGS } & \multicolumn{3}{|c|}{ Agreement between ICM and TE } & \multirow[b]{2}{*}{$\begin{array}{c}\text { Number of } \\
\text { aneuploidy/ } \\
\text { segment } \\
\text { imbalance }\end{array}$} \\
\hline & $\begin{array}{c}\text { Number of } \\
\text { consistent } \\
\text { chromosomes }\end{array}$ & $\begin{array}{l}\text { Number of } \\
\text { inconsistent } \\
\text { chromosomes } \\
\text { (CN: from } \\
\text { 3/1/0 to } 2 \text { ) }\end{array}$ & $\begin{array}{l}\text { Number of } \\
\text { inconsistent } \\
\text { chromosomes } \\
\text { (CN: from } \\
2 \text { to } 3 / 1 \text { ) }\end{array}$ & $\begin{array}{c}\text { Number of } \\
\text { consistent } \\
\text { chromosomes }\end{array}$ & $\begin{array}{c}\text { Number of } \\
\text { inconsistent } \\
\text { chromosomes }\end{array}$ & $\begin{array}{c}\text { Number of } \\
\text { mosaic } \\
\text { chromosomes }\end{array}$ & \\
\hline 1 & 1 & 1 & 0 & 46 & 0 & 0 & 0 \\
\hline 2 & 1 & 1 & 0 & 46 & 0 & 0 & 0 \\
\hline 3 & - & - & - & 46 & 0 & 0 & 1 \\
\hline 4 & 0 & 1 & 1 & 45 & 0 & 1 & - \\
\hline 5 & 1 & 1 & 0 & 46 & 0 & 0 & 1 \\
\hline 6 & 2 & 0 & 0 & 46 & 0 & 0 & 0 \\
\hline 7 & 0 & 2 & 0 & 46 & 0 & 0 & 1 \\
\hline 8 & - & - & - & 46 & 0 & 0 & 0 \\
\hline 9 & - & - & - & 46 & 0 & 0 & 0 \\
\hline 10 & 2 & 0 & 0 & 46 & 0 & 0 & 0 \\
\hline 11 & 0 & 1 & 1 & 46 & 0 & 0 & 1 \\
\hline 12 & 2 & 0 & 0 & 46 & 0 & 0 & 0 \\
\hline 13 & 2 & 0 & 0 & 45 & 0 & 1 & 0 \\
\hline $14^{\mathrm{a}}$ & 2 & 0 & 0 & - & - & - & 0 \\
\hline 15 & 1 & 1 & 0 & 46 & 0 & 0 & 0 \\
\hline 16 & - & - & - & 43 & 0 & 3 & - \\
\hline $17^{\mathrm{a}}$ & - & - & - & - & - & - & 5 \\
\hline 18 & 0 & 1 & 1 & 46 & 0 & 0 & 0 \\
\hline $19^{\mathrm{a}}$ & 1 & 1 & 0 & - & - & - & 0 \\
\hline 20 & 1 & 1 & 0 & 46 & 0 & 0 & 0 \\
\hline 21 & 2 & 0 & 0 & 46 & 0 & 0 & 0 \\
\hline 22 & 1 & 1 & 0 & 46 & 0 & 0 & 0 \\
\hline 23 & 1 & 1 & 0 & 46 & 0 & 0 & 1 \\
\hline $24^{\mathrm{a}}$ & 1 & 1 & 0 & - & - & - & 1 \\
\hline $25^{\mathrm{a}}$ & 1 & 1 & 0 & - & - & - & 0 \\
\hline 26 & 1 & 1 & 0 & 44 & 0 & 2 & - \\
\hline $27^{\mathrm{a}}$ & 2 & 0 & 0 & - & - & - & 0 \\
\hline 28 & 2 & 0 & 0 & 46 & 0 & 0 & 0 \\
\hline $29^{\mathrm{a}}$ & 1 & 1 & 0 & - & - & - & 0 \\
\hline $30^{\mathrm{a}}$ & 2 & 0 & 0 & - & - & - & 2 \\
\hline 31 & 1 & 1 & 0 & 46 & 0 & 0 & 1 \\
\hline 32 & 1 & 1 & 0 & 46 & 0 & 0 & 1 \\
\hline 33 & 2 & 0 & 0 & 46 & 0 & 0 & 0 \\
\hline 34 & 1 & 1 & 0 & 44 & 0 & 2 & - \\
\hline Rob Subtotal & 35 & 20 & 3 & 1187 & 0 & 9 & 15 \\
\hline 35 & 2 & 0 & 0 & 46 & 0 & 0 & 0 \\
\hline 36 & 0 & 2 & 0 & 46 & 0 & 0 & 0 \\
\hline 37 & - & - & - & 46 & 0 & 0 & 0 \\
\hline $38^{\mathrm{a}}$ & 1 & 1 & 0 & - & - & - & 0 \\
\hline $39^{\mathrm{a}}$ & 1 & 0 & 1 & - & - & - & 0 \\
\hline $40^{\mathrm{a}}$ & 2 & 0 & 0 & - & - & - & 3 \\
\hline 41 & 2 & 0 & 0 & 46 & 0 & 0 & 0 \\
\hline 42 & 2 & 0 & 0 & 46 & 0 & 0 & 1 \\
\hline 43 & 1 & 1 & 0 & 46 & 0 & 0 & 1 \\
\hline 44 & 2 & 0 & 0 & 46 & 0 & 0 & 1 \\
\hline $45^{\mathrm{a}}$ & 2 & 0 & 0 & - & - & - & 0 \\
\hline 46 & 1 & 1 & 0 & 46 & 0 & 0 & 0 \\
\hline Rcp Subtotal & 16 & 5 & 1 & 368 & 0 & 0 & 6 \\
\hline 47 & 0 & 1 & 0 & 46 & 0 & 0 & 2 \\
\hline 48 & 0 & 1 & 0 & 46 & 0 & 0 & 0 \\
\hline 49 & 0 & 1 & 0 & 46 & 0 & 0 & 0 \\
\hline $50^{\mathrm{a}}$ & 1 & 0 & 0 & - & - & - & 0 \\
\hline $51^{\mathrm{a}}$ & 1 & 0 & 0 & - & - & - & 0 \\
\hline Inv Subtotal & 2 & 3 & 0 & 138 & 0 & 0 & 2 \\
\hline Total & 53 & 28 & 4 & 1693 & 0 & 9 & 23 \\
\hline
\end{tabular}

${ }^{a}$ Only one NGS result is shown for embryos at the early blastocyst stage (without distinguishable ICM and TE).

is lower for chromosomes affected by Rob. This may be due to the higher propensity for acrocentric chromosomes involved in Rob (such as chromosomes 13, 14, 15,21 , and 22) to missegregate during mitosis/meiosis (Boue et al. 1985), resulting in more diverse cell lines and a higher frequency of mosaicism (Iwarsson et al. 2000, Emiliani et al. 2003).

We evaluated the validity of cleavage-stage FISHbased PGD for embryos from CR carriers by examining their blastocysts and comparing the corresponding 
results, and found a validity of only $40 \%$ in all embryos, with only about $62 \%$ of CR-associated chromosomes showing consistency between cleavage-stage FISH and blastocyst NGS results. The copy number of $\sim 87 \%$ of CR-associated chromosomes or chromosomal segments was imbalanced on day 3 but balanced on day 5/6, which was likely due to genetic mosaicism or FISH artifacts. A high rate of cleavage-stage mosaicism for CR-associated chromosomes has also been observed in other studies (Iwarsson et al. 2000, Emiliani et al. 2003); thus, analysis of one or two blastomeres may not provide an accurate indication of whole embryo chromosomal composition. Nonetheless, FISH may overestimate true cleavage-stage mosaicism (Treff et al. 2010); we found that $80 \%$ of chromosomes with copy number imbalance on day 3 and a balanced copy number on day $5 / 6$ showed loss of copy number on day 3. Technical limitations associated with FISH, including inefficient probe hybridization or signal overlap, may account for this discrepancy. Although the efficiency of the in-house locus-specific probes was pre-validated using mitotic metaphase chromosomes of cultured peripheral blood lymphocytes, they may be suboptimal with interphase nuclei of single blastomeres. Alternatively, chromosomal repair processes such as mitotic checkpoints (Encalada et al. 2005, Wei et al. 2011) and reabsorption of chromosomecontaining cytoplasmic debris (Chavez et al. 2012), which are active during embryonic development to the blastocyst stage, may be involved. The percentage of chromosomally balanced blastocysts observed in the present study $(\sim 60 \%)$ exceeds the predicted incidence of Rob carriers (1/6 normal, 1/6 carrier) (Bint et al. 2011). However, many previous studies have reported high incidence of alternate segregation in Rob carriers (Munne et al. 2000, Roux et al. 2005, Ogur et al. 2006, Chen et al. 2007, Anton et al. 2010, Pilip et al. 2014), which produces balanced gametes. In addition, the majority of embryos from Rob carriers are normal/ balanced (Jin et al. 2010), which is consistent with the current findings.

Our analyses indicate that the widely used cleavagestage FISH has limited effectiveness in PGD for embryos from balanced CR carriers. Results from cleavage-stage FISH and blastocyst NGS from the same embryos were poorly correlated, in agreement with other studies comparing cleavage-stage FISH and blastocyst-stage microarray results (Northrop et al. 2010), as well as comparative FISH analyses of cleavage- and blastocyststage embryos (Baart et al. 2004). However, in one study, blastocyst-stage embryos previously analyzed by array $\mathrm{CGH}$ were reanalyzed by FISH with remarkably consistent results (Fragouli et al. 2011), indicating that technical constraints of FISH are not solely responsible for the observed incongruence between cleavage-stage and blastocyst chromosomal composition. In addition, FISH-based PGD benefits CR carriers with improved pregnancy outcomes, which provide clinical evidence for the efficacy of FISH (Scriven et al. 2013). Nonetheless, cleavage-stage FISH is not the ideal PGD protocol for CR carriers, given that a significant proportion of embryos exhibiting balanced composition of chromosomes involved in CR had abnormalities in other chromosomes. The NGS-based PGD method was effective in detecting chromosomal imbalances as small as $\sim 7 \mathrm{Mb}$ (i.e. the loss of 22q11-22q11.21 in embryo 38 ), and the TE biopsy accurately reflected the chromosomal composition in the ICM. Therefore, blastocyst TE biopsies for NGS-based PGD can be used for the reliable detection of all chromosomes and are effective in PGD for balanced CR carriers. However, mosaic copy numbers of CR-associated chromosomes in the TE must be interpreted with caution; in addition, clinical validation of NGS-based assays is required, while the segment size of the chromosomal imbalance that can be reliably detected by NGS remains to be determined.

In conclusion, our findings demonstrate that chromosomal composition of blastocyst ICM and TE from balanced CR carriers was highly consistent. In addition, PGD results of cleavage-stage FISH analysis were poorly correlated with those obtained by NGS, with a significant proportion of blastocysts showing an imbalance by cleavage-stage FISH but judged as balanced according to NGS analysis. Thus, using blastocyst TE biopsies for NGS-based PGD is recommended for identifying chromosomal imbalance in embryos from balanced CR carriers.

\section{Declaration of interest}

The authors declare that there is no conflict of interest that could be perceived as prejudicing the impartiality of the research reported.

\section{Funding}

This work was supported by Hunan Provincial Innovation Foundation for Postgraduate (no. CX2013B089).

\section{Acknowledgements}

The authors thank the Embryology team at the Reproductive Medicine Center of Xiangya Hospital for assisting with sample preparation.

\section{References}

Alfarawati S, Fragouli E, Colls P \& Wells D 2011 First births after preimplantation genetic diagnosis of structural chromosome abnormalities using comparative genomic hybridization and microarray analysis. Human Reproduction 26 1560-1574. (doi:10.1093/humrep/ der068) 
Alves C, Sousa M, Silva J \& Barros A 2002 Preimplantation genetic diagnosis using FISH for carriers of Robertsonian translocations: the Portuguese experience. Prenatal Diagnosis 22 1153-1162. (doi:10.1002/ pd.503)

Anton E, Blanco J \& Vidal F 2010 Meiotic behavior of three D;G Robertsonian translocations: segregation and interchromosomal effect. Journal of Human Genetics 55 541-545. (doi:10.1038/jhg.2010.67)

Baart EB, Van Opstal D, Los FJ, Fauser BC \& Martini E 2004 Fluorescence in situ hybridization analysis of two blastomeres from day 3 frozen-thawed embryos followed by analysis of the remaining embryo on day 5 . Human Reproduction 19 685-693. (doi:10.1093/humrep/deh094)

Barbash-Hazan S, Frumkin T, Malcov M, Yaron Y, Cohen T, Azem F, Amit A \& Ben-Yosef D 2009 Preimplantation aneuploid embryos undergo selfcorrection in correlation with their developmental potential. Fertility \& Sterility 92 890-896. (doi:10.1016/j.fertnstert.2008.07.1761)

Bean CJ, Hunt PA, Millie EA \& Hassold TJ 2001 Analysis of a malsegregating mouse $Y$ chromosome: evidence that the earliest cleavage divisions of the mammalian embryo are non-disjunction-prone. Human Molecular Genetics 10 963-972. (doi:10.1093/hmg/10.9.963)

Bernicot I, Dechanet C, Mace A, Hedon B, Hamamah S, Pellestor F \& Anahory T 2010 Predictive value of sperm-FISH analysis on the outcome of preimplantation genetic diagnosis (PGD) for a pericentric inversion inv5(p15.3q11.2) carrier. Human Reproduction 25 1818-1823. (doi:10. 1093/humrep/deq101)

Bernicot I, Schneider A, Mace A, Hamamah S, Hedon B, Pellestor F \& Anahory T 2012 Analysis using fish of sperm and embryos from two carriers of rare $\operatorname{rob}(13 ; 21)$ and $\operatorname{rob}(15 ; 22)$ robertsonian translocation undergoing PGD. European Journal of Medical Genetics 55 245-251. (doi:10.1016/j.ejmg.2012.02.003)

Bielanska M, Tan SL \& Ao A 2002 Chromosomal mosaicism throughout human preimplantation development in vitro: incidence, type, and relevance to embryo outcome. Human Reproduction 17 413-419. (doi:10.1093/humrep/17.2.413)

Bint SM, Ogilvie CM, Flinter FA, Khalaf Y \& Scriven PN 2011 Meiotic segregation of Robertsonian translocations ascertained in cleavage-stage embryos - implications for preimplantation genetic diagnosis. Human Reproduction 26 1575-1584. (doi:10.1093/humrep/der080)

Boue A, Boue J \& Gropp A 1985 Cytogenetics of pregnancy wastage. Advances in Human Genetics 14 1-57.

Campana M, Serra A \& Neri G 1986 Role of chromosome aberrations in recurrent abortion: a study of 269 balanced translocations. American Journal of Medical Genetics 24 341-356. (doi:10.1002/ajmg. 1320240214)

Capalbo A, Bono S, Spizzichino L, Biricik A, Baldi M, Colamaria S, Ubaldi FM, Rienzi L \& Fiorentino F 2013a Sequential comprehensive chromosome analysis on polar bodies, blastomeres and trophoblast: insights into female meiotic errors and chromosomal segregation in the preimplantation window of embryo development. Human Reproduction 28 509-518. (doi:10.1093/humrep/des394)

Capalbo A, Wright G, Elliott T, Ubaldi FM, Rienzi L \& Nagy ZP 2013 b FISH reanalysis of inner cell mass and trophectoderm samples of previously array-CGH screened blastocysts shows high accuracy of diagnosis and no major diagnostic impact of mosaicism at the blastocyst stage. Human Reproduction 28 2298-2307. (doi:10.1093/humrep/ $\operatorname{det} 245)$

Chavez SL, Loewke KE, Han J, Moussavi F, Colls P, Munne S, Behr B \& Reijo Pera RA 2012 Dynamic blastomere behaviour reflects human embryo ploidy by the four-cell stage. Nature Communications 3 1251. (doi:10. 1038/ncomms2249)

Chen Y, Huang J, Liu P \& Qiao J 2007 Analysis of meiotic segregation patterns and interchromosomal effects in sperm from six males with Robertsonian translocations. Journal of Assisted Reproduction and Genetics 24 406-411. (doi:10.1007/s10815-007-9137-6)

Colls P, Escudero T, Fischer J, Cekleniak NA, Ben-Ozer S, Meyer B, Damien M, Grifo JA, Hershlag A \& Munne S 2012 Validation of array comparative genome hybridization for diagnosis of translocations in preimplantation human embryos. Reproductive Biomedicine Online 24 621-629. (doi:10.1016/j.rbmo.2012.02.006)

Conn CM, Harper JC, Winston RM \& Delhanty JD 1998 Infertile couples with Robertsonian translocations: preimplantation genetic analysis of embryos reveals chaotic cleavage divisions. Human Genetics 102 117-123. (doi:10.1007/s004390050663)
Coonen E, Martini E, Dumoulin JC, Hollanders-Crombach HT, de DieSmulders C, Geraedts JP, Hopman AH \& Evers JL 2000 Preimplantation genetic diagnosis of a reciprocal translocation $\mathrm{t}(3 ; 11)(\mathrm{q} 27.3 ; \mathrm{q} 24.3)$ in siblings. Molecular Human Reproduction 6 199-206. (doi:10.1093/ molehr/6.3.199)

Coonen E, Derhaag JG, Dumoulin JC, van Wissen LC, Bras M, Janssen M, Evers JL \& Geraedts JP 2004 Anaphase lagging mainly explains chromosomal mosaicism in human preimplantation embryos. Human Reproduction 19 316-324. (doi:10.1093/humrep/deh077)

De Braekeleer M \& Dao TN 1991 Cytogenetic studies in male infertility: a review. Human Reproduction 6 245-250.

van Echten-Arends J, Mastenbroek S, Sikkema-Raddatz B, Korevaar JC, Heineman MJ, van der Veen F \& Repping S 2011 Chromosomal mosaicism in human preimplantation embryos: a systematic review. Human Reproduction Update 17 620-627. (doi:10.1093/humupd/dmr014)

Emiliani S, Gonzalez-Merino E, Van den Bergh M, Abramowicz M \& Englert Y 2003 Higher degree of chromosome mosaicism in preimplantation embryos from carriers of robertsonian translocation $\mathrm{t}(13 ; 14)$ in comparison with embryos from karyotypically normal IVF patients. Journal of Assisted Reproduction and Genetics 20 95-100. (doi:10.1023/ A:1021796226031)

Encalada SE, Willis J, Lyczak R \& Bowerman B 2005 A spindle checkpoint functions during mitosis in the early Caenorhabditis elegans embryo. Molecular Biology of the Cell 16 1056-1070. (doi:10.1091/mbc.E04-080712)

Fiorentino F, Spizzichino L, Bono S, Biricik A, Kokkali G, Rienzi L, Ubaldi FM, lammarrone E, Gordon A \& Pantos K 2011 PGD for reciprocal and Robertsonian translocations using array comparative genomic hybridization. Human Reproduction 26 1925-1935. (doi:10. 1093/humrep/der082)

Fiorentino F, Biricik A, Bono S, Spizzichino L, Cotroneo E, Cottone G, Kokocinski F \& Michel CE 2014a Development and validation of a nextgeneration sequencing-based protocol for 24-chromosome aneuploidy screening of embryos. Fertility \& Sterility 101 1375-1382. (doi:10.1016/ j.fertnstert.2014.01.051)

Fiorentino F, Bono S, Biricik A, Nuccitelli A, Cotroneo E, Cottone G, Kokocinski F, Michel CE, Minasi MG \& Greco E 2014b Application of next-generation sequencing technology for comprehensive aneuploidy screening of blastocysts in clinical preimplantation genetic screening cycles. Human Reproduction 29 2802-2813. (doi:10.1093/humrep/ deu277)

Fragouli E, Lenzi M, Ross R, Katz-Jaffe M, Schoolcraft WB \& Wells D 2008 Comprehensive molecular cytogenetic analysis of the human blastocyst stage. Human Reproduction 23 2596-2608. (doi:10.1093/humrep/ den287)

Fragouli E, Alfarawati S, Daphnis DD, Goodall NN, Mania A, Griffiths T, Gordon A \& Wells D 2011 Cytogenetic analysis of human blastocysts with the use of FISH, CGH and aCGH: scientific data and technical evaluation. Human Reproduction 26 480-490. (doi:10.1093/humrep/ deq344)

Hamerton JL, Ray M, Abbott J, Williamson C \& Ducasse GC 1972 Chromosome studies in a neonatal population. Canadian Medical Association Journal 106 776-779.

Hamerton JL, Canning N, Ray M \& Smith S 1975 A cytogenetic survey of 14,069 newborn infants, I. Incidence of chromosome abnormalities. Clinical Genetics 8 223-243. (doi:10.1111/j.1399-0004.1975.tb01498.x)

Harrison RH, Kuo HC, Scriven PN, Handyside AH \& Ogilvie CM 2000 Lack of cell cycle checkpoints in human cleavage stage embryos revealed by a clonal pattern of chromosomal mosaicism analysed by sequential multicolour FISH. Zygote 8 217-224. (doi:10.1017/ S0967199400001015)

Huang CC, Chang LJ, Tsai YY, Hung CC, Fang MY, Su YN, Chen HF \& Chen SU 2013 A feasible strategy of preimplantation genetic diagnosis for carriers with chromosomal translocation: using blastocyst biopsy and array comparative genomic hybridization. Journal of the Formosan Medical Association 112 537-544. (doi:10.1016/j.jfma.2013. 02.010)

Huang J, Yan L, Fan W, Zhao N, Zhang Y, Tang F, Xie XS \& Qiao J 2014 Validation of multiple annealing and looping-based amplification cycle sequencing for 24-chromosome aneuploidy screening of cleavage-stage embryos. Fertility \& Sterility 102 1685-1691. (doi:10.1016/j.fertnstert. 2014.08.015) 
Iwarsson $E$, Malmgren $H$, Inzunza J, Ahrlund-Richter L, Sjoblom $P$, Rosenlund B, Fridstrom $M$, Hovatta $O$, Nordenskjold $M$ \& Blennow $E$ 2000 Highly abnormal cleavage divisions in preimplantation embryos from translocation carriers. Prenatal Diagnosis 20 1038-1047. (doi:10. 1002/1097-0223(200012)20:13<1038::AID-PD976>3.0.CO;2-8)

Jacobs PA, Melville M, Ratcliffe S, Keay AJ \& Syme J 1974 A cytogenetic survey of 11,680 newborn infants. Annals of Human Genetics 37 359-376. (doi:10.1111/j.1469-1809.1974.tb01843.x)

Jin H, Ping L, Jie Q, Ying L \& Yongjian C 2010 Translocation chromosome karyotypes of the Robertsonian translocation carriers' embryos. Fertility \& Sterility 93 1061-1065. (doi:10.1016/j.fertnstert. 2008.11.020)

Ko DS, Cho JW, Lee HS, Kim JY, Kang IS, Yang KM \& Lim CK 2013 Preimplantation genetic diagnosis outcomes and meiotic segregation analysis of robertsonian translocation carriers. Fertility \& Sterility 99 1369-1376. (doi:10.1016/j.fertnstert.2012.12.010)

Lejeune J 1963 Autosomal disorders. Pediatrics 32 326-337.

Liu J, Wang W, Sun X, Liu L, Jin H, Li M, Witz C, Williams D, Griffith J \& Skorupski J 2012 DNA microarray reveals that high proportions of human blastocysts from women of advanced maternal age are aneuploid and mosaic. Biology of Reproduction 87 148. (doi:10.1095/biolreprod. 112.103192)

Malmgren $H$, Sahlen S, Inzunza J, Aho $M$, Rosenlund B, Fridstrom $M$, Hovatta O, Ahrlund-Richter L, Nordenskjold M \& Blennow E 2002 Single cell $\mathrm{CGH}$ analysis reveals a high degree of mosaicism in human embryos from patients with balanced structural chromosome aberrations. Molecular Human Reproduction 8 502-510. (doi:10.1093/molehr/ 8.5.502)

Munne S, Escudero T, Sandalinas M, Sable D \& Cohen J 2000 Gamete segregation in female carriers of Robertsonian translocations. Cytogenetics and Cell Genetics 90 303-308. (doi:10.1159/000056793)

Munne S, Escudero T, Fischer J, Chen S, Hill J, Stelling JR \& Estop A 2005a Negligible interchromosomal effect in embryos of Robertsonian translocation carriers. Reproductive Biomedicine Online 10 363-369. (doi:10.1016/S1472-6483(10)61797-X)

Munne S, Velilla E, Colls P, Garcia Bermudez M, Vemuri MC, Steuerwald N, Garrisi J \& Cohen J 2005b Self-correction of chromosomally abnormal embryos in culture and implications for stem cell production. Fertility \& Sterility 84 1328-1334. (doi:10.1016/ j.fertnstert.2005.06.025)

Northrop LE, Treff NR, Levy B \& Scott RT Jr 2010 SNP microarray-based 24 chromosome aneuploidy screening demonstrates that cleavage-stage FISH poorly predicts aneuploidy in embryos that develop to morphologically normal blastocysts. Molecular Human Reproduction $\mathbf{1 6}$ 590-600. (doi:10.1093/molehr/gaq037)

Ogur G, Van Assche E, Vegetti W, Verheyen G, Tournaye H, Bonduelle M, Van Steirteghem A \& Liebaers I 2006 Chromosomal segregation in spermatozoa of 14 Robertsonian translocation carriers. Molecular Human Reproduction 12 209-215. (doi:10.1093/molehr/ gah253)

Otani T, Roche M, Mizuike M, Colls P, Escudero T \& Munne S 2006 Preimplantation genetic diagnosis significantly improves the pregnancy outcome of translocation carriers with a history of recurrent miscarriage and unsuccessful pregnancies. Reproductive Biomedicine Online 13 869-874. (doi:10.1016/S1472-6483(10)61037-1)

Pellestor F, Sele B, Jalbert H \& Jalbert P 1989 Direct segregation analysis of reciprocal translocations: a study of 283 sperm karyotypes from four carriers. American Journal of Human Genetics 44 464-473.

Pilip L, Spinenko LA, Zukin VD \& Bil'ko NM 2014 Meiotic segregation of chromosomes 13 and 14 of heterozygous Robertsonian translocation $\operatorname{der}(13 ; 14)$ (q10; q10) carriers. TSitologiia i Genetika 48 48-53.

Pujol A, Durban M, Benet J, Boiso I, Calafell JM, Egozcue J \& Navarro J 2003 Multiple aneuploidies in the oocytes of balanced translocation carriers: a preimplantation genetic diagnosis study using first polar body. Reproduction 126 701-711. (doi:10.1530/rep.0.1260701)

Pujol A, Benet J, Staessen C, Van Assche E, Campillo M, Egozcue J \& Navarro J 2006 The importance of aneuploidy screening in reciprocal translocation carriers. Reproduction 131 1025-1035. (doi:10.1530/rep. 1.01063)
Roux C, Tripogney C, Morel F, Joanne C, Fellmann F, Clavequin MC \& Bresson JL 2005 Segregation of chromosomes in sperm of Robertsonian translocation carriers. Cytogenetic and Genome Research 111 291-296. (doi:10.1159/000086902)

Scriven PN, Flinter FA, Khalaf Y, Lashwood A \& Mackie Ogilvie C 2013 Benefits and drawbacks of preimplantation genetic diagnosis (PGD) for reciprocal translocations: lessons from a prospective cohort study. European Journal of Human Genetics 21 1035-1041. (doi:10.1038/ ejhg.2013.9)

Stern C, Pertile M, Norris H, Hale L \& Baker HW 1999 Chromosome translocations in couples with in vitro fertilization implantation failure. Human Reproduction 14 2097-2101. (doi:10.1093/humrep/14.8.2097)

Tan YQ, Tan K, Zhang SP, Gong F, Cheng DH, Xiong B, Lu CF, Tang XC, Luo KL \& Lin G 2013 Single-nucleotide polymorphism microarray-based preimplantation genetic diagnosis is likely to improve the clinical outcome for translocation carriers. Human Reproduction 28 2581-2592. (doi:10.1093/humrep/det271)

Treff NR, Levy B, Su J, Northrop LE, Tao X \& Scott RT Jr 2010 SNP microarray-based 24 chromosome aneuploidy screening is significantly more consistent than FISH. Molecular Human Reproduction 16 583-589. (doi:10.1093/molehr/gaq039)

Treff NR, Northrop LE, Kasabwala K, Su J, Levy B \& Scott RT Jr 2011 Single nucleotide polymorphism microarray-based concurrent screening of 24-chromosome aneuploidy and unbalanced translocations in preimplantation human embryos. Fertility \& Sterility 95 1606-1612-e16011602. (doi:10.1016/j.fertnstert.2010.11.004)

Van Assche E, Staessen C, Vegetti W, Bonduelle M, Vandervorst M, Van Steirteghem A \& Liebaers I 1999 Preimplantation genetic diagnosis and sperm analysis by fluorescence in situ hybridization for the most common reciprocal translocation $\mathrm{t}(11 ; 22)$. Molecular Human Reproduction 5 682-690. (doi:10.1093/molehr/5.7.682)

van Uum CM, Stevens SJ, Dreesen JC, Drusedau M, Smeets HJ, Hollanders-Crombach B, Die-Smulders CE, Geraedts JP, Engelen JJ \& Coonen E 2012 SNP array-based copy number and genotype analyses for preimplantation genetic diagnosis of human unbalanced translocations. European Journal of Human Genetics 20 938-944. (doi:10.1038/ ejhg.2012.27)

Wang L, Cram DS, Shen J, Wang X, Zhang J, Song Z, Xu G, Li N, Fan J \& Wang S 2014 Validation of copy number variation sequencing for detecting chromosome imbalances in human preimplantation embryos. Biology of Reproduction 91 37. (doi:10.1095/biolreprod.114. 120576)

Wei Y, Multi S, Yang CR, Ma J, Zhang QH, Wang ZB, Li M, Wei L, Ge ZJ \& Zhang CH 2011 Spindle assembly checkpoint regulates mitotic cell cycle progression during preimplantation embryo development. PLOS ONE 6 e21557. (doi:10.1371/journal.pone.0021557)

Wells D, Kaur K, Grifo J, Glassner M, Taylor JC, Fragouli E \& Munne S 2014 Clinical utilisation of a rapid low-pass whole genome sequencing technique for the diagnosis of aneuploidy in human embryos prior to implantation. Journal of Medical Genetics 51 553-562. (doi:10.1136/ jmedgenet-2014-102497)

Wong CC, Loewke KE, Bossert NL, Behr B, De Jonge CJ, Baer TM \& Reijo Pera RA 2010 Non-invasive imaging of human embryos before embryonic genome activation predicts development to the blastocyst stage. Nature Biotechnology 28 1115-1121. (doi:10.1038/nbt.1686)

Zong C, Lu S, Chapman AR \& Xie XS 2012 Genome-wide detection of single-nucleotide and copy-number variations of a single human cell. Science 338 1622-1626. (doi:10.1126/science.1229164)

Received 28 May 2015

First decision 6 July 2016

Revised manuscript received 8 January 2016

Accepted 28 January 2016 